\title{
First isolation and Genetic characterization of G8P[8] rotavirus strains emerged recently from Guangzhou, China
}

\author{
Si-Jie Wang \\ Fudan University \\ Li-Na Chen \\ Fudan University \\ Song-Mei Wang \\ Fudan University \\ Hong-Lu Zhou \\ Fudan University \\ Chao Qiu \\ Fudan University \\ Baoming Jiang \\ Centers for Disease Control and Prevention \\ Tian-Yi Qiu \\ Fudan University \\ Sheng-Li Chen \\ Southern Medical University \\ Xuan-Yi Wang ( $\nabla$ xywang@shmu.edu.cn) \\ Fudan University
}

\section{Research Article}

Keywords: Gastroenteritis, Rotavirus, Emergence, China, Genotyping

Posted Date: March 2nd, 2022

DOI: https://doi.org/10.21203/rs.3.rs-1345303/v1

License: @) (i) This work is licensed under a Creative Commons Attribution 4.0 International License. Read Full License 


\begin{abstract}
Background The G[8] genotype rotavirus has been detected frequently in children in many countries and even became the predominant strain in sub-Saharan Africa countries. While there are almost no reports from China. In our study, the whole genome sequences of G8 rotavirus strains in China was reported for the first time, and phylogenetic analysis was performed on them.

Methods Virus isolation and subsequent next-generation sequencing were performed for those confirmed G8P[8] specimens. The genetic characteristics and evolutionary relationship were analyzed in comparison with those epidemic rotavirus strains derived from GenBank.

Results The two Guangzhou G8 strains were DS-1-like with the closest genetic distance to strains circulating in Southeast Asia, and the VP7 gene of the two strains was derived from human $\mathrm{G} 8$ rotavirus instead of animal-derived rotavirus. The large genetic distance indicated that the isolated Guangzhou strains might not be directly introduced from Southeast Asian countries. Instead, it might be produced by reassortment between G8P[8] and other genotype strains circulated in Southeast Asia in recent years.
\end{abstract}

Conclusions This is the first report of the whole genome sequence information of G8 rotavirus strain in China. The clinical and epidemiological significance of these $\mathrm{G} 8$ strains in China remains to be further monitored.

\title{
Background
}

Despite significant advances in fighting childhood diarrhea through sanitation improvement, and vaccine introduction, diarrheal diseases remained worldwide the fourth cause of death for children $<5$ years of age in 2016(1), and human rotavirus (RV) infection remains the leading cause of severe acute gastroenteritis (AGE). Population-based diarrhea surveillance in children $<5$ years of age measured an incidence rate of $45.6-54.7$ RV cases per thousand children per year in South and North of China, with the highest Vesikari score in comparison with infection caused by calicivirus, astrovirus, and enteric adenovirus(2).

Rotaviruses are members of the genus Rotavirus within the family Reoviridae, with a genome of 11 segments of double-stranded RNA (dsRNA), encoding six structural viral proteins (VP1-4, VP6, and VP7) and six non-structural proteins (NSP1-5/6)(3). Based on the sequences of VP4 and VP7 proteins, RVs are divided into different $P$ (VP4) and G (VP7) genotypes, respectively. Globally, six G types (G1-4, G9, and G12) and three $P$ types (P[4], P[6], and P[8]) were predominated in the past decades $(4,5)$. Data from the Chinese RV sentinel surveillance network indicated that the predominant $\mathrm{G}$ type in China was $\mathrm{G} 9(\sim$ $80 \%)$, followed by G3 ( 10\%) since $2012, \mathrm{G} 1, \mathrm{G} 2$, and G4 were very rarely reported(6), and the genotype of G8 was not been discovered before. In the present study, we describe the detection and genetic characterization of two G8P[8] strains in stool samples from infants with severe AGE in Guangzhou, China.

\section{Materials And Methods}

\section{Participants and Specimens Collection}

A hospital-based study on hospitalized acute gastroenteritis caused by rotavirus infection in children less than 5 years was conducted. Between December 2020 and February 2021, 16 children < 5 years were hospitalized for treatment of severe AGE(7) in Zhujiang Hospital, Guangzhou, fecal samples were collected from each child at the admission for laboratory diagnosis as one of the routine clinical procedures. This study was reviewed and approved by the Institutional Review Board (IRB) of the Institutes of Biomedical Sciences, Fudan University.

\section{Rotavirus antigen detection, RNA Extraction and RT-PCR}

A commercial enzyme immunoassay (EIA) (Ridascreen, R-Biopharm AG, Germany) was applied for RV detection.(8) Those RV antigen positive specimens were further diluted with phosphate buffered saline (PBS), and then clarified by centrifugation for ten minutes at $8000 \mathrm{r} / \mathrm{min}$. RNA was extracted from the suspensions using the Nucleic Acid Extraction Kit (Tianlong, Xian, China). Subsequently, RT-PCR was applied to analyze G and P genotypes with primers (Beg9, End9, Con3, Con2) as described elsewhere $(9,10)$. The amplicons were analyzed by electrophoresis on a $1 \%$ agarose gel. Sanger sequencing of obtained amplicons (1062 bp for VP7 and 887 bp for VP4) was performed and analyzed with the BLAST database to determine the G and P genotypes.

\section{Whole-Genome Sequencing}

Library preparation and Illumina sequencing were performed by a commercial provider (Tsingke, China). Using fastp (https://github.com/OpenGene/fastp) as a tool to remove sequence adapters and low-quality bases at the 3 'end, and the retention ratios of reads after processing were between $97 \%$ and $98 \%$. The sequences were aligned with the corresponding NCBI database through bbmap series software to remove the corresponding rRNA, host, and bacterial sequences. SPAdes and SOAPdenovo software were used to de novo assembly of the second-generation sequence data. The spliced sequences were aligned with the virus-NT database for BLAST (V2.10.0+) alignment.

\section{Phylogenetic analysis of rotavirus $\mathbf{G}$ and $P$ genotypes}

Original data of strains and reference sequences that were more similar to the sequenced strains from the GenBank database were downloaded. DNAMAN software was used for sequence similarity analysis. Multiple alignments and phylogenetic analysis were performed with MEGA X software. The phylogenetic trees were constructed using the Neighbor-joining method. Kimura-2 parameter model and gamma distribution were used to calculate genetic distance, and reliability analyses were performed using the Bootstrap method, repeated sampling 1000 times, less than $70 \%$ was considered meaningless. The percentages 
of nucleotide-sequence similarity between Guangzhou RVA strains and RVA sequences deposited in the GenBank were calculated using the p-distances method.

\section{Construction of background RV strains}

The whole genome sequenced rotavirus genome data, mainly from Asia and Africa, were screened in the GenBank, and strains of the same genotype in the same region and the same time period were excluded. Finally, the complete genome sequence of 46 representative strains of human group $A$ rotaviruses from all over the world were selected as reference sequences (Table 1). Phylogenetic trees were constructed for 11 gene fragments. Strains with high similarity and close genetic distance to the two Guangzhou G8 strains were obtained in each segment to determine whether the two strains had reassortment between the segments. 
Table 1

Comparison of the genome constellations of the G8P[8] strains with other RVA complete genomes from representative strains reported in GenBank

Strain

Origin VP7 VP4 VP6

VP1 VP2

V2 VP3

NSP1 NSP2

NSP3 NSP4

NSP5/6 Shared

genotyp

$\begin{array}{lllllllllllllllll}\text { RVA/Human-wt/CHN/GZ- } & \text { Human } & \text { G8 } & \text { P[8] } & \text { I2 } & \text { R2 } & \text { C2 } & \text { M2 } & \text { A2 } & \text { N2 } & \text { T2 } & \text { E2 } & \text { H2 }\end{array}$

0005/2021/G8P[8]

RVA/Human-wt/CHN/GZ-

0013/2021/G8P[8]

RVA/Human-wt/THA/SSKT-

269/2014/G8P[8]

RVA/Human-wt/THA/SSL

55/2014/G8P[8]

RVA/Human-wt/THA/SKT-

457/2014/G8P[8]

RVA/Human-wt/THA/PCB-

85/2013/G8P[8]

RVA/Human-wt/SGP/NV-16-

$124 / 2016 / G 8 P[8]$

RVA/Human-

wt/VNM/RVN1326/2014/G8P[8]

RVA/Human-

wt/JPN/17287/2019/G8P[8]

RVA/Human-

wt/JPN/S01162/2017/G8P[8]

RVA/Human-wt/KOR/CAU17L

79/2017/G8P[8]

RVA/Human-

wt/COD/DRC88/2003/G8P[8]

RVA/Human-wt/THA/DBM2017

203/2017/G9P[8]

RVA/Human-wt/THA/DBM2018

291/2018/G9P[8]

RVA/Human-

wt/ESP/SS61921417/2015/G3P[8]

RVA/Human-

wt/ESP/SS96217158/2015/G3P[8]

RVA/Human-

wt/ESP/SS61720845/2015/G3P[8]

RVA/Human-wt/TWN/2014/103-701-

D022/G3P[8]

RVA/Human-

tc/IND/69M/1980/G8P[10]

RVA/Human-

wt/COD/DRC86/2003/G8P[6]

RVA/Human-wt/MLL/Mali-

119/2008/G8P[6]

RVA/Human-wt/UGA/MUL-13-

308/2013/G8P[6]

RVA/Human-

wt/MWI/BID1B9/2012/G8P[4]

RVA/Human-

wt/KEN/KDH1111/2011/G8P[4]

RVA/Human-

wt/USA/2009727045/2009/G8P[4]

RVA/Human-wt/THA/DBM2018-

105/2018/G2P[4]

RVA/Human-tc/USA/DS-1/1976/G2P[4]

RVA/Human-wt/GHA/GH019-

08/2008/G8P[6]

$\begin{array}{llllllllllll}\text { Human } & \text { G8 } & \text { P[8] } & \text { I2 } & \text { R2 } & \text { C2 } & \text { M2 } & \text { A2 } & \text { N2 } & \text { T2 } & \text { E2 } & \text { H2 } \\ \text { Human } & \text { G8 } & \text { P[8] } & \text { I2 } & \text { R2 } & \text { C2 } & \text { M2 } & \text { A2 } & \text { N2 } & \text { T2 } & \text { E2 } & \text { H2 }\end{array}$

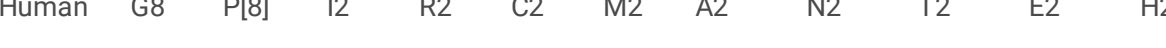

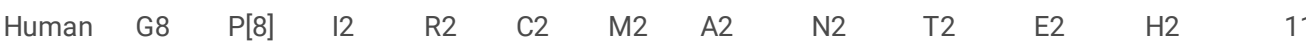

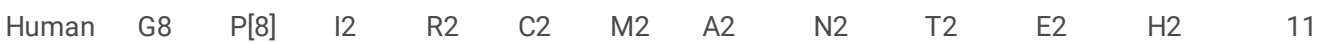

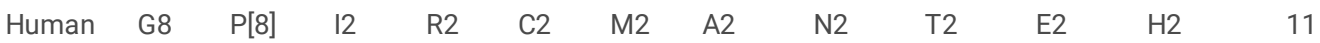

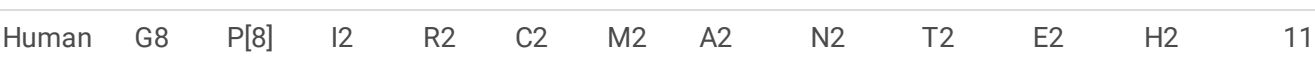

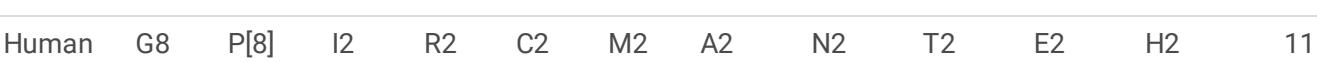

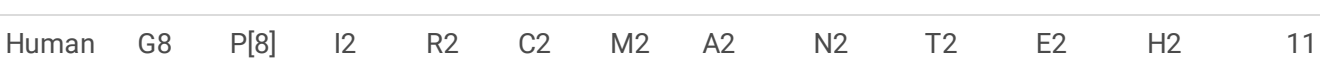

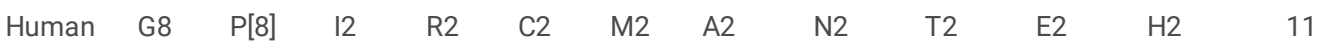

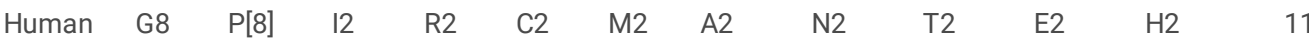

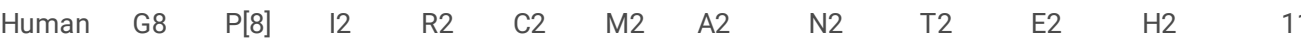

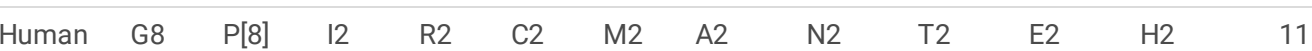

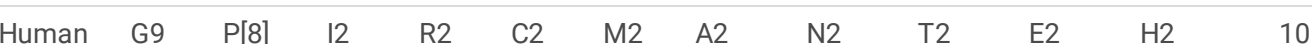

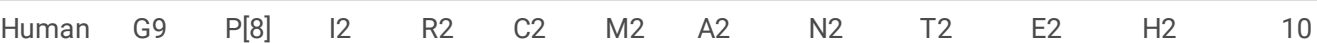

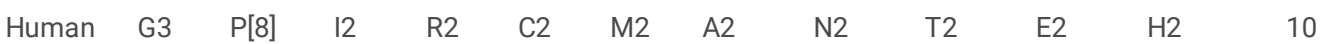

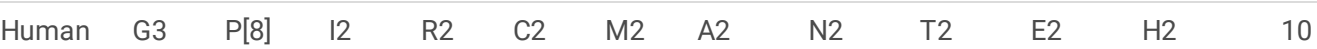

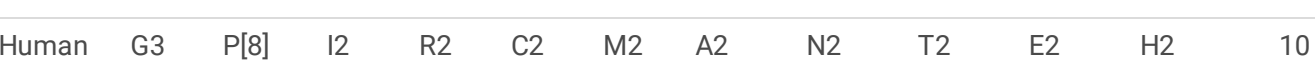

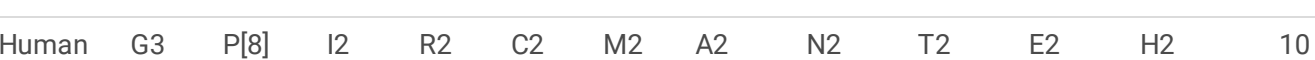

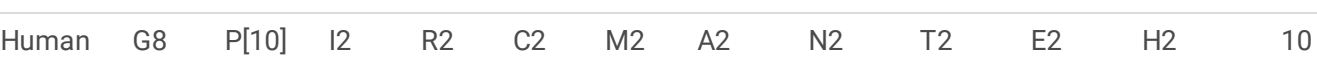

$\begin{array}{lllllllllllll}\text { Human } & \mathrm{G} 8 & \mathrm{P}[6] & \text { I2 } & \text { R2 } & \text { C2 } & \text { M2 } & \text { A2 } & \text { N2 } & \text { T2 } & \text { E2 } & \text { H2 } & 10\end{array}$

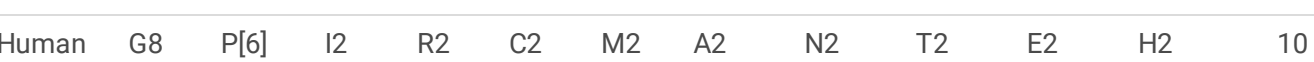

\begin{tabular}{|c|c|c|c|c|c|c|c|c|c|}
\hline Human G8 & $\mathrm{P}[6]$ & 12 & R2 & $\mathrm{C} 2$ & M2 & $\mathrm{A} 2$ & N2 & T2 & $\mathrm{H} 2$ \\
\hline
\end{tabular}

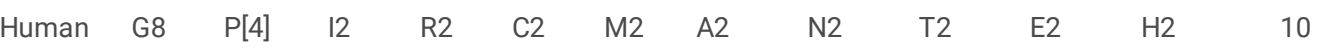

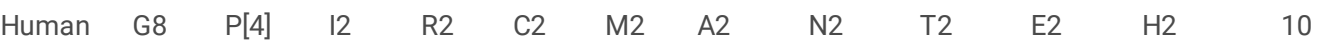

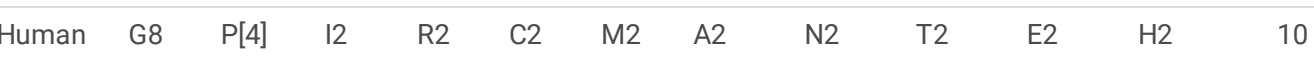

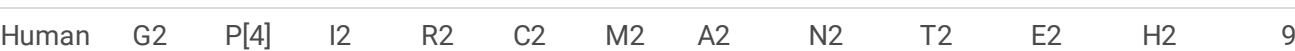

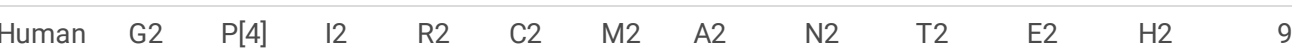

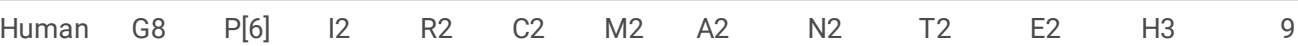




\begin{tabular}{|c|c|c|c|c|c|c|c|c|c|c|c|c|c|}
\hline Strain & Origin & VP7 & VP4 & VP6 & VP1 & VP2 & VP3 & NSP1 & NSP2 & NSP3 & NSP4 & NSP5/6 & $\begin{array}{l}\text { Shared } \\
\text { genotyp }\end{array}$ \\
\hline RVA/Human-wt/PAK419/2016/G3P[4] & Human & G3 & $\mathrm{P}[8]$ & 12 & R2 & $\mathrm{C} 2$ & M2 & $\mathrm{A} 2$ & N2 & $\mathrm{T} 1$ & E2 & $\mathrm{H} 2$ & 9 \\
\hline $\begin{array}{l}\text { RVA/Human- } \\
\text { Wt/USA/2014737554/2014/G1P[8] }\end{array}$ & Human & G1 & $\mathrm{P}[8]$ & 12 & R2 & $\mathrm{C} 2$ & M2 & A2 & N2 & T2 & E2 & $\mathrm{H} 1$ & 9 \\
\hline RVA/Cow-wt/ZAF/1604/2007/G8P[1] & Bovine & G8 & $\mathrm{P}[1]$ & 12 & R2 & $\mathrm{C} 2$ & M2 & A3 & N2 & T6 & E2 & H3 & 7 \\
\hline RVA/Cow-tc/THA/A5-13/1988/G8P[1] & Bovine & G8 & $\mathrm{P}[1]$ & 12 & R2 & $\mathrm{C} 2$ & M2 & A14 & N2 & T6 & E2 & $\mathrm{H} 3$ & 7 \\
\hline $\begin{array}{l}\text { RVA/Human- } \\
\text { wt/US/2012841174/2012/G8P[14] }\end{array}$ & Human & G8 & $\mathrm{P}[14]$ & 12 & R3 & $\mathrm{C} 2$ & M2 & A3 & N2 & T6 & E2 & H3 & 6 \\
\hline $\begin{array}{l}\text { RVA/Human- } \\
\text { wt/HRV/CR2006/2006/G8P[8] }\end{array}$ & Human & G8 & $\mathrm{P}[8]$ & 11 & $\mathrm{R} 1$ & C1 & M1 & A1 & N1 & T1 & E1 & $\mathrm{H} 1$ & 2 \\
\hline $\begin{array}{l}\text { RVA/Human- } \\
\text { wt/TUN/6862/2000/G8P[8] }\end{array}$ & Human & G8 & $\mathrm{P}[8]$ & 11 & $\mathrm{R} 1$ & C1 & M1 & $\mathrm{A} 1$ & $\mathrm{~N} 1$ & T1 & E1 & $\mathrm{H} 1$ & 2 \\
\hline $\begin{array}{l}\text { RVA/Human- } \\
\text { Wt/CHN/km15119/2016/G9P[8] }\end{array}$ & Human & G9 & $\mathrm{P}[8]$ & 11 & $\mathrm{R} 1$ & C1 & M1 & $\mathrm{A} 1$ & $\mathrm{~N} 1$ & $\mathrm{~T} 1$ & E1 & $\mathrm{H} 1$ & 1 \\
\hline $\begin{array}{l}\text { RVA/Human-wt/MLI/Mali- } \\
\text { 138/2008/G9P[8] }\end{array}$ & Human & G9 & $\mathrm{P}[8]$ & 11 & $\mathrm{R} 1$ & C1 & M1 & $\mathrm{A} 1$ & $\mathrm{~N} 1$ & T1 & E1 & $\mathrm{H} 1$ & 1 \\
\hline RVA/Human-lab/USA/Wa/2020/G1P[8] & Human & G1 & $\mathrm{P}[8]$ & 11 & $\mathrm{R} 1$ & $\mathrm{C} 1$ & M1 & A1 & $\mathrm{N} 1$ & $\mathrm{~T} 1$ & E1 & $\mathrm{H} 1$ & 1 \\
\hline $\begin{array}{l}\text { RVA/Human-wt/ZAF/UFS-NGS-MRC- } \\
\text { DPRU4269/2002/G1P[8] }\end{array}$ & Human & G1 & $\mathrm{P}[8]$ & 11 & $\mathrm{R} 1$ & C1 & M1 & A1 & $\mathrm{N} 1$ & $\mathrm{~T} 1$ & E1 & $\mathrm{H} 1$ & 1 \\
\hline $\begin{array}{l}\text { RVA/Human- } \\
\text { wt/CHN/E5365/2017/G1P[8] }\end{array}$ & Human & G1 & $\mathrm{P}[8]$ & 11 & $\mathrm{R} 1$ & $\mathrm{C} 1$ & M1 & $\mathrm{A} 1$ & $\mathrm{~N} 1$ & $\mathrm{~T} 1$ & E1 & $\mathrm{H} 1$ & 1 \\
\hline $\begin{array}{l}\text { RVA/Human- } \\
\text { wt/CHN/E5867/2018/G3P[8] }\end{array}$ & Human & G3 & $\mathrm{P}[8]$ & 11 & $\mathrm{R} 1$ & $\mathrm{C} 1$ & M1 & $\mathrm{A} 1$ & $\mathrm{~N} 1$ & $\mathrm{~T} 1$ & E1 & $\mathrm{H} 1$ & 1 \\
\hline $\begin{array}{l}\text { RVA/Human-wt/UGA/NSA-13- } \\
\text { 043/2013/G9P[8] }\end{array}$ & Human & G9 & $\mathrm{P}[8]$ & 11 & $\mathrm{R} 1$ & $\mathrm{C} 1$ & M1 & $\mathrm{A} 1$ & $\mathrm{~N} 1$ & $\mathrm{~T} 1$ & E1 & $\mathrm{H} 1$ & 1 \\
\hline $\begin{array}{l}\text { RVA/Human- } \\
\text { wt/USA/3000357125/2016/G9P[8] }\end{array}$ & Human & G9 & $\mathrm{P}[8]$ & 11 & $\mathrm{R} 1$ & $\mathrm{C} 1$ & M1 & $\mathrm{A} 1$ & $\mathrm{~N} 1$ & $\mathrm{~T} 1$ & E1 & $\mathrm{H} 1$ & 1 \\
\hline $\begin{array}{l}\text { RVA/Human- } \\
\text { wt/USA/3000354346/2015/G12P[8] }\end{array}$ & Human & G12 & $\mathrm{P}[8]$ & 11 & $\mathrm{R} 1$ & $\mathrm{C} 1$ & M1 & $\mathrm{A} 1$ & $\mathrm{~N} 1$ & $\mathrm{~T} 1$ & E1 & $\mathrm{H} 1$ & 1 \\
\hline RVA/Human/CHN/WZ606/2013/G3P[9] & Human & G3 & $\mathrm{P}[9]$ & 13 & R3 & C3 & M3 & A3 & N3 & T3 & E3 & $\mathrm{H} 3$ & 0 \\
\hline RVA/Human- tc/JPN/AU-I/1982/G3P[9] & Human & G3 & $\mathrm{P}[9]$ & 13 & R3 & C3 & M3 & A3 & N3 & T3 & E3 & H3 & 0 \\
\hline
\end{tabular}

\section{Results}

\section{Genotypes and genetic characteristics of Guangzhou $\mathrm{G8}$ rotavirus}

Five of sixteen samples collected from hospitalized AGE children were positive for rotavirus. Further G/P typing determined these positive samples into two G8P[8] strains, two G9P[8] strains and one G2P[4] strain. The 11 gene fragments of the two G8P[8] strains designated as GZ-0005 and GZ-0013 were amplified, original gels are presented in Supplementary Figure S1.

\section{Whole-genome sequencing}

The whole-genome sequence of the two Guangzhou G8P[8] strains were generated (GenBank accession nos. OK349178 - OK349199) (Table S1). The wholegenome analysis further confirmed that these two strains were DS-1-like strains with a genotype constellation of G8-P[8]-I2-R2-C2-M2-A2-N2-T2-E2-H2 (Table 1). The whole genome of the two G8 strains were highly similar with overall genome identify of $99.78 \%$ and the sequence identity of 11 gene fragments were ranging from $99.47-99.96 \%$.

\section{Large evolutionary distance between two Guangzhou G8P[8] and other circulating G8P[8] strains}

Ten representative G8P[8] strains isolated in other areas shared the same genotype in all 11 gene fragments with two Guangzhou strains (Table 1). Of these, eight G8P[8] strains isolated between 2013 and 2019 were adopted for analysis. The whole genome sequence identity between the eight G8P[8] strains and the two studied strains varied relative widely from $87.23-95.21 \%$. For each individual gene fragment, VP2, VP3, VP4, VP7, NSP1, and NSP3 could reach a sequence identity over $98 \%$ in some strains, while the sequence identities of other gene fragments were relatively low (Table S2). 


\section{Phylogenetic Analysis of G8P[8] Genotype VP7, VP4 Segments}

We used the full length of the VP7 and VP4 gene sequences to construct phylogenetic trees. The nucleotide similarities of the two Guangzhou G8 strains and the Thailand strain (SSKT-269/THA/G8P[8]) were 99.34\% and 99.15\% (Table 2). From the phylogenetic tree of VP7 genes, the two Guangzhou strains were clustered exclusively with DS-1-like G8 strains formerly described in multiple regions such as Singapore, Japan, Thailand, and Korea (lineage 1). In addition, several G8 bovine rotaviruses in Southeast Asia (BE4/IND/G8P[1], 79/IND/G8P[14], A5-13/THA/G8P[14], A5/THA/G8Px) were also located on lineage 1. Other clusters of G8 genotypes in lineage 3 were constituted with Wa-like RVA strains, which were isolated in America (2009727045/USA/G8P[4]), African countries (6862/TUN/G8P[8]), and European countries (CR2006/HRV/G8P[8], SI-885/SVN/G8P[8]). Other African DS-1-like G8 strains were clustered into a distinct lineage 2. (Fig. 1)

Table 2

Sequence alignment results of 11 fragment amplified products of G8P[8] strains (GZ-0005 and GZ-0013)

\begin{tabular}{|c|c|c|c|}
\hline Gene Name & Closest Strain & GenBank accession No. & Identity \%* \\
\hline \multirow[t]{2}{*}{ VP1 } & \multirow[t]{2}{*}{ RVA/Human-wt/THA/DBM2018-105/2018/G2P[4] } & \multirow[t]{2}{*}{ LC514525 } & $99.57 \%$ \\
\hline & & & $99.48 \%$ \\
\hline \multirow[t]{2}{*}{ VP2 } & \multirow[t]{2}{*}{ RVA/Human-wt/THA/DBM2017-203/2017/G9P[8] } & \multirow[t]{2}{*}{ LC514482 } & $99.51 \%$ \\
\hline & & & $99.55 \%$ \\
\hline \multirow[t]{2}{*}{ VP3 } & \multirow[t]{2}{*}{ RVA/Human-wt/ESP/SS61921417/2015/G3P[8] } & \multirow[t]{2}{*}{ KU550277 } & $99.50 \%$ \\
\hline & & & $99.50 \%$ \\
\hline \multirow[t]{2}{*}{ VP4 } & \multirow[t]{2}{*}{ RVA/Human-wt/THA/DBM2018-291/2018/G9P[8] } & \multirow[t]{2}{*}{ LC514495 } & $99.45 \%$ \\
\hline & & & $99.53 \%$ \\
\hline \multirow[t]{2}{*}{ NSP1 } & \multirow[t]{2}{*}{ RVA/Human-wt/ESP/SS96217158/2015/G3P[8] } & \multirow[t]{2}{*}{ KU550302 } & $99.62 \%$ \\
\hline & & & $99.30 \%$ \\
\hline \multirow[t]{2}{*}{ VP6 } & \multirow[t]{2}{*}{ RVA/Human-wt/THA/DBM2017-016/2017/G9P[8] } & \multirow[t]{2}{*}{ LC514474 } & $99.48 \%$ \\
\hline & & & $99.48 \%$ \\
\hline \multirow[t]{2}{*}{ NSP3 } & \multirow[t]{2}{*}{ RVA/Human-wt/ESP/SS61720845/2015/G3P[8] } & \multirow[t]{2}{*}{ KU550311 } & $99.06 \%$ \\
\hline & & & $99.06 \%$ \\
\hline \multirow[t]{2}{*}{ NSP2 } & \multirow[t]{2}{*}{ RVA/Human-wt/ESP/SS61720845/2015/G3P[8] } & \multirow[t]{2}{*}{ KU550305 } & $99.43 \%$ \\
\hline & & & $99.53 \%$ \\
\hline \multirow[t]{2}{*}{ VP7 } & \multirow[t]{2}{*}{ RVA/Human-wt/THA/SSKT-269/2014/G8P[8] } & \multirow[t]{2}{*}{ LC169956 } & $99.34 \%$ \\
\hline & & & $99.15 \%$ \\
\hline \multirow[t]{2}{*}{ NSP4 } & \multirow[t]{2}{*}{ RVA/Human-wt/ESP/SS61720845/2015/G3P[8] } & \multirow[t]{2}{*}{ KU550317 } & $99.45 \%$ \\
\hline & & & $98.91 \%$ \\
\hline \multirow[t]{2}{*}{ NSP5/6 } & \multirow[t]{2}{*}{ RVA/Human-wt/THA/DBM2018-291/2018/G9P[8] } & \multirow[t]{2}{*}{ LC514502 } & $99.75 \%$ \\
\hline & & & $99.63 \%$ \\
\hline
\end{tabular}

We further analyzed the VP7 nucleotide sequence similarities between the Guangzhou G8 strains and the DS-1-like G8 strains in Southeast Asia were very close $(0.0066 \sim 0.0114)$. However, the genetic distances between the Guangzhou strains and the DS-1-like G8 strains in Africa were far ( $0.1476 \sim 0.1678)$. In addition, the genetic distances between the two Guangzhou strains and the Wa-like G8 strains were even farther with the genetic distance over 0.1689(Table S3). The sequence identities between the Guangzhou strains and bovine strains were ranging from $97.51-98.66 \%$, lower than that between Guangzhou strains and human G8 strains (over 99\%).

For VP4 gens, strain DBM2018-291/THA/G9P[8] circulating in Thailand had the highest sequence similarity (99.45-99.53\%) (Table 2) and the closest averaged genetic distance (0.0079) against two Guangzhou strains. Also, we observed ten G8P[8] strains circulating in Southeast Asia and East Asia from 2013-2019, and one strain of DS-1-like G8P[8] in the Czech Republic in another branch rather than the two Guangzhou strains, indicating close genetic distance of other circulating G8P[8] strains (Fig. 2). More importantly, it is worth noting that the VP4 genes of other P[8] strains in China from 2016 to 2019 are far away from the two Guangzhou G8P[8] strains (Fig. 2).

\section{Genogrouping analysis of whole genomes and reassortment analysis}


The VP1 genes of the two Guangzhou strains had the highest sequence similarity with Thailand 2018 G2P[4] strain. The VP2, VP4, VP6, and NSP5/6 genes of the two strains had the highest sequence similarity with Thailand 2017-2018 G9P[8] strains. The VP3, NSP1, NSP2, and NSP3 genes had the highest similarity with the Spanish G3P[8] strain in 2015. The most similar sequence for the two Guangzhou G8P[8] strains except for VP7 genes were come from G2P[4], G3P[8] and G9P[8] rather than circulating G8P[8] strains. Detailed similarity score can be found in Table 2.

Furthermore, all 11 gene fragments were analyzed through phylogenetic tree, which involving the two Guangzhou G8P[8] strains and other 47 RV strains derived from GenBank. For each gene fragment, we focus on the location of: 1) the two Guangzhou G8P[8] strains (red dot); 2) RV strains with the highest sequence similarity with the two Guangzhou strains (purple diamond); 3) other G8P[8] strains circulating globally (blue triangle), and 4) other RV strains circulating in China (brown square). The results showed that, except for VP7 gene, the two Guangzhou G8P[8] strains located in neither the branch of other circulating G8P[8] strains, nor RV strains circulating in China. It could be seen that the VP1 (Fig. 3A), VP2 (Fig. 3B), VP4 (Fig. 3D), NSP1 (Fig. 3G), NSP2 (Fig. $3 \mathrm{H}$ ), and NSP5/6 (Fig. 3K) gene fragments of the two Guangzhou strains were located in the same branch with Thailand G9P[8] strain in 2018 (DBM2018291). The VP3 (Fig. 3C) and VP6 (Fig. 3E) genes has the closest genetic distance to Thailand 2017 G9P[8] strains (DBM2017-016). NSP3 (Fig. 3I) and NSP4 (Fig. 3J) genes were genetically the closest to GER33-15/DEU/G3P[8]. The VP7 genes of the two Guangzhou strains were genetically closer to G8 strains including G8P[8], G8P[1], G8P[4], G8P[6] and G8P[14] (Fig. 3F), and the other 10 gene fragments were genetically distant from the G8P[8] strains in various regions and at various times. Instead, they had relatively close genetic distances with G9P[8], G3P[8],and G2P[4] circulating strains in Thailand, Vietnam, Spain, Germany and other places during 2015-2018 (Fig. 3A 3K).

\section{Discussion}

This is the first full genome analysis of G8P[8] rotavirus discovered in China. We conducted a comprehensive analysis for the two Guangzhou strains, including the whole genome sequencing of all 11 genes. It is well known that G[8] genotype is one of the common RV strain in bovine(11). It was first discovered in humans specimens in Indonesia between 1979 and 1981 in the form of an "ultra-short" electrophoretic pattern(12, 13). Since then, the G8 strain has been detected in children in many countries and even became one of the dominant strains in some of sub-Saharan Africa countries(14). Even though G8 strains were circulating in multiple countries surrounding China, for instance, India(15), Iran(16), Vietnam(17), Thailand(18), Singapore(19) and Japan(18), it was extremely rare in China so far(20). In fact, more than ten thousand rotavirus gene sequences were submitted from China. Of those, only one strain was identified as G8 strain (G17011060/CHN/G8P[8]). In this study, out of five RV antigen positive samples, two positive were confirmed as G8P[8] strains. Moreover, during the same epidemic season, from an ongoing multi-center RV vaccine effectiveness study among infants with severe AGE, G8P[8] strains were determined in an incredible high proportion: Huizhou (25.0\%), Shunde (55.6\%), Shenzhen (42.1\%) in Guangdong Province, Mianyan (36.4\%) in Sichuan Province, and Xiamen (11.1\%), Fujian Province (personal communication). Worldwide, G1, G2, G3, G4, and G9 was recognized as globally important rotavirus genotype, and successive replacement among these genotypes was observed. In China, between 1998 and 2000, the predominant strains causing AGE in children less than five years old was G1 (72.7\%)(21); afterwards, G1 type decreased from 70\% before 2000 to $20 \%$, while G3 type rose from $33.2-43 \%(22)$. Around year 2010, G9 strains increased significant, and eventually replaced the dominance of G3 strain. A dominance strain replacement cycle of about ten years could thus be inferred. Combined with the findings from our studies, it might indicate that predominance of G9 strains would be replaced probably by G8 strains in China. Of course, this needs to be further monitored by more surveillance data.

Serotype $\mathrm{G} 8$ rotaviruses are rarely found in man and the exchange of genes between human and bovine G8 viruses may have occurred on more than one occasion(23). G8 reassortment strains are currently considered to have two major lineages, one is strains originating in Africa(24, 25), and another is strains originating in Southeast Asia(17). In the BEAST analysis performed by Hoa-Tran et al., the hypothesis that the G8P[8] strains in Southeast Asia were produced by reassortment of bovine G8 strain and human DS-1-like strain was verified, and it was estimated that the reassortment event occurred between 2007 and 2012(17). In our study, the whole genome sequencing results suggested that, although the VP7 genes of the two Guangzhou G8P[8] strains displayed high gene homology $(91.90 ~ 97.93 \%$ ) with those bovine strains derived in Southeast Asia, however, higher gene homology (99.40 99.59\%) was found between the two Guangzhou strains and the DS-1-like G8P[8] strains circulating in Southeast Asia in recent years. Therefore, it is hard to conclude that the two Guangzhou strains originated from the recombination between animal and human strains. Secondly, the whole genome sequence of the two Guangzhou isolates were also different from those DS-1-like G8 and Wa-like G8 strains derived from Africa and Europe, with regard to sequence similarities and genetic distances. Thirdly, further whole genome sequence comparison between the two Guangzhou strains and those G8P[8] strains circulated recently in Southeast Asia and East Asia indicated that the similarity were incredibly low, especially the similarity on VP1, VP6, NSP2 NSP4, and NSP5/6 genes. Conversely, except for the VP7 gene, higher similarity were observed on other 10 gene segments between the two Guangzhou strains and those circulating G9P[8], G3P[8] and G2P[4] strains derived in Thailand and Spain between 2014 and 2018. Hence, it is most likely that the two Guangzhou strains originated from the recombination of G8P[8], G9P[8], and G3P[8] strains circulating in Southeast Asia in recent years, rather than the accumulation of variation or the recombination between human and bovine strains.

One limitation of our study was that only two G8P[8] strains in Guangzhou were isolated and sequenced. The analysis on prevalence, evolution and origins might not be represent the characteristics of G8P[8] strains spread in China. Nevertheless, in the past epidemic season, at least, we have noticed the emergency of G8 strain not only in Guangzhou, but also in the other south regions of China. It would be very valuable to study the evolution-associated characteristics with more G8 strains that might spread elsewhere, to further verify our hypothesis on the origins of emerged G8P[8] in China.

\section{Conclusions}

Probably due to the frequent personnel mobility and trade, the G8 genotype, which used to circulate in countries around China for years, has recently emerged in the South of China, and accounted for a considerable proportion of children presented as severe AGE. The clinical and epidemiological significance of this G8 strain in China remains to be further monitored. 


\section{Abbreviations}

RV: rotvirus

AGE: severe acute gastroenteritis

RT-PCR: Reverse Transcription-Polymerase Chain Reaction

\section{Declarations}

\section{Ethics approval and consent to participate}

This study was reviewed and approved by the Institutional Review Board (IRB) of the Institutes of Biomedical Sciences, Fudan University (registration number: 2020-001). Fecal sample collection is a routine testing requirement for children with diarrhea in hospitals. Collection of fecal samples will not cause any harm to the patients. This article does not involve any personal information about the patients, so there is no need to sign an informed consent form.

\section{Consent for publication}

Not applicable.

\section{Availability of data and materials}

The datasets generated during the current study are available in the GenBank sequence database. GenBank accession nos. OK349178 - OK349199.

\section{Competing interests}

The authors declare that they have no competing interests.

\section{Funding}

This work was supported in part by grants from the National Science and Technology Major Projects for Significant New Drugs Development (2018ZX09739002-006).

\section{Authors' contributions}

Song-Mei Wang, Sheng-Li Chen, and Xuan-Yi Wang contributed to the study's conception and design. Sheng-Li Chen recruited participants and collected specimens. Si-Jie Wang, Li-Na Chen, Song-Mei Wang, Hong-Lu Zhou, and Chao Qiu carried-out the laboratory analyses on clinical samples. Si-Jie Wang, Li-Na Chen, and Tian-Yi Qiu conducted the bioinformatics analysis. Si-Jie Wang, Tian-Yi Qiu, and Xuan-Yi Wang wrote the paper. Baoming Jiang provided important contribution in the writing of the paper.

All authors provided important input to methods of the study, revised the manuscript, and approved the final version.

All authors had full access to all the data in the study and had final responsibility for the decision to submit for publication.

\section{Acknowledgements}

We acknowledge the seed funding from the Shanghai Institute of Infectious Disease and Biosecurity.

\section{References}

1. Mokomane M, Kasvosve I, Melo Ed, Pernica JM, Goldfarb DM. The global problem of childhood diarrhoeal diseases: emerging strategies in prevention and management. Therapeutic advances in infectious disease. 2018;5(1):29-43. DOI: https://doi.org/10.1177\%2F2049936117744429

2. Wang J-X, Zhou H-L, Mo Z-J, Wang S-M, Hao Z-Y, Li Y, et al. Burden of viral gastroenteritis in children living in rural China: Population-based surveillance. International Journal of Infectious Diseases. 2020;90:151-160. DOI: https://doi.org/10.1016/j.ijid.2019.10.029

3. Sadiq A, Bostan N, Yinda KC, Naseem S, Sattar S. Rotavirus: Genetics, pathogenesis and vaccine advances. Reviews in medical virology. 2018;28(6):e2003. DOI: https://doi.org/10.1002/rmv.2003

4. Organization WH. Rotavirus vaccines: WHO position paper-January 2013. Weekly Epidemiological Record = Relevé épidémiologique hebdomadaire. 2013;88(05):49-64. DOI: https://doi.org/10.1016/j.vaccine.2013.05.037

5. Santos N, Hoshino Y. Global distribution of rotavirus serotypes/genotypes and its implication for the development and implementation of an effective rotavirus vaccine. Reviews in medical virology. 2005;15(1):29-56. DOI: https://doi.org/10.1002/rmv.448

6. Chinese Preventive Medicine Association. Expert consensus on immunoprophylaxis of childhood rotavirus gastroenteritis (2020 version). Chinese Journal of Epidemiology, 2020, 41(0): 0-0. DOI: http://dx.doi.org/10.3760/cma.j.cn112338-20201103-01298

7. Velázquez FR, Matson DO, Calva JJ, Guerrero ML, Morrow AL, Carter-Campbell S, et al. Rotavirus infection in infants as protection against subsequent infections. New England Journal of Medicine. 1996;335(14):1022-1028. DOI: 10.1056/NEJM199610033351404 
8. Eing BR, May G, Baumeister HG, Kühn JE. Evaluation of two enzyme immunoassays for detection of human rotaviruses in fecal specimens. Journal of clinical microbiology. 2001;39(12):4532-4534. DOI: https://doi.org/10.1128/JCM.39.12.4532-4534.2001

9. Fujii Y, Nakagomi T, Nishimura N, Noguchi A, Miura S, Ito H, et al. Spread and predominance in Japan of novel G1P[8] double-reassortant rotavirus strains possessing a DS-1-like genotype constellation typical of G2P[4] strains. Infect Genet Evol. 2014;28:426-433. DOI: https://doi.org/10.1016/j.meegid.2014.08.001

10. World Health Organization. Manual of rotavirus detection and characterization methods. World Health Organization; 2009. http://whqlibdoc.who.int/hq/2008/WHO_IVB_08.17_eng.pdf

11. Taniguchi K, Urasawa T, Urasawa S. Independent segregation of the VP4 and the VP7 genes in bovine rotaviruses as confirmed by VP4 sequence analysis of G8 and G10 bovine rotavirus strains. Journal of general virology. 1993;74(6):1215-1221. DOI: https://doi.org/10.1099/0022-1317-74-6-1215

12. Hasegawa A, Inouye S, Matsuno S, Yamaoka K, Eko R, Suharyono W. Isolation of human rotaviruses with a distinct RNA electrophoretic pattern from Indonesia. Microbiology and immunology. 1984;28(6):719-722. DOI: https://doi.org/10.1111/j.1348-0421.1984.tb00726.x

13. Albert MJ. Detection of human rotaviruses with a super-short RNA pattern. Acta paediatrica scandinavica. 1985;74(6):975-976. DOI: https://doi.org/10.1111/j.1651-2227.1985.tb10069.x

14. Tapia MD, Armah G, Breiman RF, Dallas MJ, Lewis KD, Sow SO, et al. Secondary efficacy endpoints of the pentavalent rotavirus vaccine against gastroenteritis in sub-Saharan Africa. Vaccine. 2012;30:A79-A85. DOI: https://doi.org/10.1016/j.vaccine.2012.01.022

15. Jagannath M, Vethanayagam RR, Reddy BY, Raman S, Rao CD. Characterization of human symptomatic rotavirus isolates MP409 and MP480 having 'long'RNA electropherotype and subgroup I specificity, highly related to the P6 [1], G8 type bovine rotavirus A5, from Mysore, India. Archives of virology. 2000;145(7):1339-1357. DOI: https://doi.org/10.1007/s007050070094

16. Modaress S, Rahbarimanesh AA, Edalat R, Sohrabi A, Motamedirad M, Modarres S, et al. Human rotavirus genotypes detection among hospitalized children, a study in Tehran, Iran. Archives of Iranian medicine. 2011;14(1):39-45. DOI: https://dx.doi.org/011141/AIM.009

17. Hoa-Tran TN, Nakagomi T, Vu HM, Do LP, Gauchan P, Agbemabiese CA, et al. Abrupt emergence and predominance in Vietnam of rotavirus A strains possessing a bovine-like G8 on a DS-1-like background. Arch Virol. 2016;161(2):479-482. DOI: https://doi.org/10.1007/s00705-015-2682-x

18. Kondo K, Tsugawa T, Ono M, Ohara T, Fujibayashi S, Tahara Y, et al. Clinical and Molecular Characteristics of Human Rotavirus G8P[8] Outbreak Strain, Japan, 2014. Emerg Infect Dis. 2017;23(6):968-972. DOI: https://dx.doi.org/10.3201\%2Feid2306.160038

19. Chia G, Ho HJ, Ng CG, Neo FJ, Win MK, Cui L, et al. An unusual outbreak of rotavirus G8P[8] gastroenteritis in adults in an urban community, Singapore, 2016. J Clin Virol. 2018;105:57-63. DOI: https://doi.org/10.1016/j.jcv.2018.06.004

20. Yu J, Lai S, Geng Q, Ye C, Zhang Z, Zheng Y, et al. Prevalence of rotavirus and rapid changes in circulating rotavirus strains among children with acute diarrhea in China, 2009-2015. Journal of Infection. 2019;78(1):66-74. DOl: https://doi.org/10.1016/j.jinf.2018.07.004

21. Fang Z-Y, Yang H, Qi J, Zhang J, Sun L-W, Tang J-Y, et al. Diversity of rotavirus strains among children with acute diarrhea in China: $1998-2000$ surveillance study. Journal of clinical microbiology. 2002;40(5):1875-1878. DOI: https://doi.org/10.1128/JCM.40.5.1875-1878.2002

22. L Y. Molecular Epidemiologic Study on Rotavirus Diarrhea Among Children Less Than 5 Years of Age (in Chinese): Fudan University; 2013.

23. Cooney M, Gorrell R, Palombo E. Characterisation and phylogenetic analysis of the VP7 proteins of serotype G6 and G8 human rotaviruses. Journal of medical microbiology. 2001;50(5):462-467. DOI: https://doi.org/10.1099/0022-1317-50-5-462

24. Esona M, Geyer A, Page N, Trabelsi A, Fodha I, Aminu M, et al. Genomic characterization of human rotavirus G8 strains from the African rotavirus network: relationship to animal rotaviruses. Journal of medical virology. 2009;81(5):937-951. DOI: https://doi.org/10.1002/jmv.21468

25. Nakagomi T, Doan YH, Dove W, Ngwira B, Iturriza-Gómara M, Nakagomi O, et al. G8 rotaviruses with conserved genotype constellations detected in Malawi over 10 years (1997-2007) display frequent gene reassortment among strains co-circulating in humans. J Gen Virol. 2013;94(Pt 6):1273-1295. DOI: https://dx.doi.org/10.1099\%2Fvir.0.050625-0

\section{Figures}

\section{Figure 1}

See image above for figure legend.

\section{Figure 2}

See image above for figure legend.

\section{Figure 3}

See image above for figure legend. 


\section{Supplementary Files}

This is a list of supplementary files associated with this preprint. Click to download.

- SupplementaryMaterials.docx 